\title{
ANALYTICAL MODEL TO PREDICT POLLUTION FLASHOVER VOLTAGES OF PORCEALIN DISC INSULATORS
}

\author{
Chandrashekhar A BADACHI*, Pradipkumar DIXIT** \\ ${ }^{*}$ Research Scholar, Jain University, and \\ Asst.Professor, Dept. of EEE, Acharya Institute of Technology Bangalore, \\ e-mail:chandru.badachi@gmail.com \\ ** Associate Professor, Department of Electrical and Electronics Engineering, \\ M S Ramaiah Institute of Technology, Bangalore
}

\begin{abstract}
In this paper, a new mathematical model is proposed to predict the pollution flashover voltages of porcelain disc insulators subject to AC voltages. The pollution flashover mechanism is most commonly influenced by the parameters such as applied voltage, pollution resistance, arc length and arc constants. The proposed model is developed by establishing the relation between the above said parameters using the dimensional analysis. The Ayrton's arc constants $A$ and $n$ used in the model are estimated using optimization of the published experimental data of arc voltage and arc current of a real insulator. For a number of insulators of different geometrical dimensions, the pollution flashover voltages are computed using the new proposed model and are compared with experimental and analytical results of other researchers of the same insulators. It is found that the computed results are in good accordance with the experimental and analytical results of other researchers.
\end{abstract}

Keywords: Ceramic insulators, Flashover, Pollution, Modelling

\section{INTRODUCTION}

With the rapid growth of industrial sector and changes in lifestyle of the people, the need for electrical energy has been increasing day by day and thus widening the gap between generation and demand. To minimize this gap, the electrical power has been transferred at higher voltage levels. Due to rise in the voltage levels, the performance of insulators has been affected by the effect of polluted atmospheric conditions in the field and as a result of it the insulators have been found to be failing at working or system voltages only. The Eskom [1] a South African electricity public utility has recorded a total of 12,000 outages of transmission line over a period of 16 years from 1993 to 2009 . The entire study revealed that a total of $89 \%$ of outages were mainly due to pollution flashover of insulators, birds, lightning, and fire. It is clear from the result of the study that the pollution flashover of insulators is still a serious threat in achieving a safe and successful operation of the transmission network. The problem of pollution induced failure of insulators has been investigated in many ways, such as natural testing of insulators, artificial pollution flashover testing of insulators in laboratories and a mathematical approach to predict the pollution induced flashover voltages. The natural testing method suffers from the limitations such as, it requires more time to test the insulators and also it is not an economical procedure. The limitation with artificial testing of insulators is difficult to mimic the practical scenario of pollution distribution and wetting of the insulators. Therefore the mathematical modelling of polluted insulators to predict the pollution induced flashover voltages is more effective and economical. From the literature, it is observed that to predict the pollution induced flashover voltages of porcelain insulators, flat plate glass / porcelain model of rectangular [2-4] triangular shape $[5,6]$ and cylindrical model [7] has been used in place of actual insulator. The pollution induced discharges in the above said models may not be in the same way as in case of actual insulator because the arc formed would be certainly on the surface of the model and also steam formed may readily disperse. In actual insulator, the scintillations/arc develops on the underside of the insulator from pin towards the edge through several ribs of insulator and also the steam developed by the arc may confine to the underside and it cannot readily disperse as in flat plate case. This may make a considerable difference. Hence, above said models may not represent the actual insulators. The intelligent systems such as artificial neural networks [8], support vector machines [9], fuzzy logic [10], FEM [11, 12] and Wavelet Transform [13] have also been adopted in the prediction of pollution induced flashover voltages. The accuracy of such prediction may be confined to only to the insulators which have been used in the prediction of flashover voltages. There are models developed [14, 15] based on the real insulators, but in such models the number of parameters involved are more hence increasing the complexity of the model.

With respect to the above discussions, the present study deals with the development of a mathematical model based on geometrical parameters of a real insulator to predict the pollution induced flashover voltages of porcelain disc insulators under varying pollution conditions. The type of pollution in the field varies from place to place such as marine pollution, desert pollution and industrial pollution. In the present study marine pollution is considered to pollute the insulators.

\section{DEVELOPMENT OF MATHEMATICAL MODEL}

The pollution flashover mechanism can be analysed into different phases and are

I- Accumulation of contaminants

II- Wetting of the surface

III- Formation of Dry bands 
IV- Arcing of dry bands which may lead to flashover

In the above phases, phase (III) and (IV) mainly depends on phases (I) and (II). In practice, the phases (I) and (II) are non-uniform in nature resulting in multiple dry bands and multiple arcing. It would be difficult to bring in all these complicated phases in the development of the model, therefore certain assumptions are made in the development of the model and they are, insulator will have uniform pollution distribution across its surface, uniform wetting of its surface and only one arc will be dominant on the surface leading to flashover.

From the literature, it is observed that the most of the common factors characterizing the pollution flashover phenomena are pollution resistance $\left(\mathrm{R}_{\mathrm{p}}\right)$, arc length $\left(\mathrm{L}_{\mathrm{arc}}\right)$, applied voltage $\left(\mathrm{V}_{\mathrm{s}}\right)$ and $\operatorname{arc}$ constants $(\mathrm{A} \& \mathrm{n})$. The above factors are considered in the development of a mathematical model, which will represent the pollution flashover phenomena. The dimensional analysis is used in the model to establish the relation between the above said factors. A relation between theses parameters can be written with the help of function ' $\mathrm{f}$ ' and is given as

$\mathrm{V}_{\mathrm{s}}=\mathrm{f}\left(\mathrm{A}, \mathrm{R}_{\mathrm{p}},\left(\mathrm{L}_{\mathrm{arc}}\right)\right)$

Where ' $\mathrm{f}$ ' is an unknown function.

A matrix is formed in terms of the fundamental dimensional units of the considered factors in the form of $\mathrm{M} \mathrm{L} \mathrm{T} \mathrm{I} \mathrm{as}$ mass, length, time and current respectively. For example voltage $\left(\mathrm{V}_{\mathrm{s}}\right)$ is written in its fundamental dimensional unit as $\left(\mathrm{M}^{1} \mathrm{~L}^{2} \mathrm{~T}^{3} \mathrm{I}^{-1}\right) \mathrm{M}=1, \mathrm{~L}=2, \mathrm{~T}=-3$ and $\mathrm{I}=-1$

Then the dimensional matrix is given by

\begin{tabular}{c|cccc} 
& $V S$ & $A$ & $\left(L_{\text {arc }}\right)$ & $R_{p}$ \\
\hline$M$ & 1 & 1 & 0 & 1 \\
$L$ & 2 & 1 & 1 & 1 \\
$T$ & -3 & -3 & 0 & -3 \\
$I$ & -1 & $n-1$ & 0 & -2
\end{tabular}

The rank of the above matrix is found to be 3 and the numbers of variables are 4 , therefore as per the Bukingham$\pi$ theorem [16] the solution can be in the form of 1 independent dimensionless product $(\pi)$. The parameters $A$, $\mathrm{R}_{\mathrm{p}}$, and ( $\mathrm{L}_{\mathrm{arc}}$ ) are considered as repeated variables, then the left out parameter $\mathrm{V}_{\mathrm{s}}$ is the dimensionless product and can be written as

$\Pi=A^{a}\left(L_{a r c}\right)^{b} R_{p}^{c}$

Where $\mathrm{a}, \mathrm{b}$ and $\mathrm{c}$, are the exponents of $\operatorname{arc}$ constant $\mathrm{A}$, arc length $\left(\mathrm{L}_{\mathrm{arc}}\right)$ and pollution resistance $\mathrm{Rp}$ respectively. Since the objective of the present work is to predict the pollution flashover voltages, hence $\Pi$ can be written with the fundamental dimensions of the repeated variables as

$\Pi=\left[M L T^{3} I^{n-1}\right]^{a}[L]^{b}\left[M L T^{-3} I^{-2}\right]^{c}$

(3) Now the modified equation of $V_{s}$ in terms of ESDD is

$\left[M L^{2} T^{-3} I^{-1}\right]=\left[M L T^{-3} I^{n-1}\right]^{a}[L]^{b}\left[M L T^{-3} I^{-2}\right]^{c}$ given by

The solution of equation (4) is obtained by equating the exponents of the fundamental units on both right hand side and left hand side of the equation (4)

$1=a_{1}+c_{1}$

$2=a_{1}+c_{1}$

$-3=-3 a_{1}-3 c_{1}$

$-1=(n-1) a_{1}-2 c_{1}$

The obtained solution is

$\mathrm{a}=1 / \mathrm{n}+1, \mathrm{~b}=1$ and $\mathrm{c}=\mathrm{n} / \mathrm{n}+1$

Now substituting the power exponents and the equation for $\mathrm{Vs}$ becomes

$V S=K(A)^{\frac{1}{(n+1)}}\left(L_{a r c}\right)^{1}\left(R_{p}\right)^{\frac{n}{n+1}}$

Thus the equation for Vs is rewritten as

$V S=K A^{\frac{1}{n+1}}\left(R_{p}\right)^{\frac{n}{n+1}}\left(L_{\text {arc }}\right)$

Where ' $\mathrm{K}$ ' is the dimensional constant and is found using experimental data in the further sections

Equation (10) can be modified to predict the flashover voltages by replacing the arc length $L_{\text {arc }}$ by critical arc length $\left(\mathrm{L}_{\mathrm{arc}}\right)_{\mathrm{c}}$. Hence the equation (10) becomes

$V_{f o}=K A^{\frac{1}{n+1}}\left(R_{p}\right)^{\frac{n}{n+1}}\left(\left(L_{a r c}\right)_{c}\right)$

The above equation (11) can be used to estimate the pollution flashover voltages, when the pollution condition is given in terms of pollution resistance $\left(R_{p}\right)$. However, if the pollution condition is given in terms of layer conductivity then in the equation (11) $R_{p}$ is replaced in terms of layer conductivity and can be written as.

$V_{f o}=K A^{\frac{1}{n+1}}\left(\frac{F F}{K_{s}\left(L-\left(L_{\text {arc }}\right)_{c}\right)}\right)^{\frac{n}{n+1}}\left(\left(L_{a r c}\right)_{c}\right)$

Where $\mathrm{FF}$ is the form factor of the insulator, $\mathrm{K}_{\mathrm{s}}$ is the layer conductivity and $\mathrm{L}$ is the total leakage distance. Now above equation (12) can be used to predict the pollution flashover voltages when pollution condition is given in terms of layer conductivity. In practice, even equivalent salt deposit density (ESDD) is also used to express the pollution condition. Now to account for ESDD, which is the amount of salt in the deposit on a given surface of the insulator divided by area of surface, the equation (12) can be modified by uttering $\mathrm{K}_{\mathrm{s}}$ in terms of ESDD with the help of a power fit given in(13) from the values of ESDD and $\mathrm{K}_{\mathrm{s}}$ referred from[17].

$\mathrm{K}_{\mathrm{s}}=86^{*} \mathrm{ESDD}^{0.9}$

$V_{f o}=K A^{\frac{1}{n+1}}\left(\frac{F F}{\left(86 * E S D D^{0.9}\right)\left(L-(\operatorname{Larc})_{c}\right)}\right)^{\frac{n}{n+1}}\left(\left(L_{\text {arc }}\right)_{c}\right)$ 
Now, the equation (14) can be used to compute the pollution flashover voltages, for a given pollution condition in terms of ESDD. The critical arc length $\left(L_{a r c}\right)_{c}$ is calculated [18] as

$\left(L_{\text {arc }}\right)_{c}=\frac{L}{n+1}$

From the equation (14), it is clear that for a given insulator and ESDD, total leakage distance $\mathrm{L}$ and form factor FF are known and $\left(L_{a r c}\right)_{c}$ is calculated using equation (15) after knowing the value of ' $n$ ', constants A, $n$ and dimensional constant $\mathrm{K}$ are the only unknowns. The next section discusses estimation of Ayrton's arc constants A and n.

\section{ESTIMATION OF AYRTON'S ARC CONSTANTS A \& n}

From the literature [18], it is seen that The Ayrton's arc equation of the form shown below

$\mathrm{E}_{\mathrm{arc}}=\mathrm{A} \mathrm{I}^{-\mathrm{n}}$

has been used in most of the mathematical models. The models developed based on equation (16), have used different Ayrton's arc constants A and $\mathrm{n}$. The Table 1 above shows the values of Ayrton's arc constants A and $\mathrm{n}$ adopted by different researchers in their mathematical models. From the Table 1 it is clear that the arc constant $\mathrm{A}$ and $\mathrm{n}$ lie in the wide range of values $31-500(\mathrm{~V} / \mathrm{cm})$ and 0.24 to 1.13 respectively. It is also observed that arc constants $\mathrm{A}$ and $\mathrm{n}$ have been determined from the experimental arc voltage and arc current based on cylindrical model [6] and triangular glass plate [7] instead of real insulator. However, authors [19] have determined the arc constants A and $n$ using arc voltages and arc currents obtained from a real life insulator. Authors [19] have conducted experiments on a real life insulator to obtain arc voltages and arc currents for different ESDD and different arc lengths. The experimental data of arc currents and arc voltages for different ESDD and different arc lengths obtained on a real insulator [19] are used in the equation (16) and as a result of it, a system of 63 equations with unknown arc constants $\mathrm{A}$ and $\mathrm{n}$ are formulated. To optimize the arc constants, the equation (16) is rewritten to form an objective function as shown below in (17)

$\sum_{\mathrm{k}=1}^{\mathrm{m}}\left[\left((\right.\right.$ Earc $\left.)-\mathrm{f}\left(\mathrm{A} * \mathrm{I}^{-\mathrm{n}}\right)\right]$

Where ' $\mathrm{m}$ ' is number of equations

The constraints for the arc constant $\mathrm{A}$ and $\mathrm{n}$ for the above objective function (17) are defined by the values of A and $\mathrm{n}$ given in Table 1 as given below

\section{$530 \leq \mathrm{A} \geq 31$}

$1.13 \leq \mathrm{n} \geq 0.24$

The formulated 63 equations are solved using an optimization toolbox in MATLAB. The resulted optimum values for Ayrton's arc constants A and n are $66 \mathrm{~V} / \mathrm{cm}$ and
0.7 respectively. The obtained arc constant values are compared with experimentally published data [19] and are found in good agreement with each other. Further, the estimated optimum values of $\mathrm{A}$ and $\mathrm{n}$ are used in the proposed model (14) to compute the pollution induced flashover voltages. Now in the equation (13), the only unknown is dimensional constant ' $\mathrm{K}$ ' and is estimated experimentally. Therefore, next section discusses, the details of experiments carried out.

Table 1 Ayrton's arc constants A and n used by different researchers

\begin{tabular}{|c|c|c|c|}
\hline Author's & $\begin{array}{c}\text { Year } \\
\text { [Ref.] }\end{array}$ & $A($ V/cm $)$ & $n$ \\
\hline Obenus & $1958[20]$ & 100 & 0.7 \\
\hline Alston & $1963[21]$ & 63 & 0.76 \\
\hline Claverie et al & $1973[22]$ & 100 & 0.5 \\
\hline Jolly et al & $1974[23]$ & 296 & 0.397 \\
\hline Rumeli & $1976[24]$ & 518 & 0.273 \\
\hline Rahal \&Hurraux & $1979[25]$ & 530 & 0.24 \\
\hline El-Arbaty et al & $1979[26]$ & 40 & 0.8 \\
\hline Verma M P & $1983[27]$ & 53.45 & 0.5 \\
\hline Guan and Zhang & $1990[28]$ & 140 & 0.67 \\
\hline Topalis et al & $1992[15]$ & 131.5 & 0.374 \\
\hline R. P. Singh et al & $1994[29]$ & 31 to100 & 0.43 to \\
\hline $\begin{array}{c}\text { Ghosh and } \\
\text { Chaterjee }\end{array}$ & $1995[30]$ & 360 & 0.98 \\
\hline Farag et al & $1997[32]$ & 530 & 0.24 \\
\hline M. Farzaneh et al & $2000[33]$ & 205 & 0.56 \\
\hline Holtzhausen & $2001[34]$ & 59 & 0.53 \\
\hline $\begin{array}{c}\text { Gonos and } \\
\text { Topalis }\end{array}$ & $2002[35]$ & 124.8 & 0.409 \\
\hline $\begin{array}{c}\text { Hussein } \\
\text { Hemmatjou }\end{array}$ & $2006[31]$ & 100.25 & 0.6577 \\
\hline $\begin{array}{c}\text { Boubakeur } \\
\text { Zegnini et al }\end{array}$ & $2007[36]$ & 197.418 & 0.593 \\
\hline Dixit et al & $2009[19]$ & 68 & 0.65 \\
\hline Y. Sabri et al & $2010[6]$ & 168 & 0.325 \\
\hline Yawei Li et al & $2014[7]$ & 65.8 & 1.13 \\
$($ Bottom $)$ \\
\hline (Bottom)
\end{tabular}

\section{EXPERIMENT DETAILS}

In the present work, experiments are carried out with the arrangement of the set up as shown in the figure. 1 with a pollution chamber of dimension $2.75 \mathrm{~m} \times 2.75 \mathrm{~m} \times 2.75 \mathrm{~m}$ and source of $400 \mathrm{~V} / 60 \mathrm{kV}, 60 \mathrm{kVA}$ with $\mathrm{R} / \mathrm{X}$ ratio 0.3 . Solid layer method is adopted to pollute the test insulators and for the testing Procedure-A is followed as per standards IEC507 [17]. The porcelain insulators designated as Type $\mathrm{A}$ and Type $\mathrm{B}$ are used in the experiments whose dimensional details are given in Table 2 .

Test Preparation: Insulator under study is cleaned thoroughly to get rid of any contaminants present on it and dried completely. The commercial sodium chloride $\mathrm{NaCl}$ 
is used to get conductivity and Kaolin as binding agent to mimic the marine pollution. A slurry composed of these two materials in a proportion as mentioned in IEC507 [17] is prepared with tap water $(90 \mu \mathrm{S} / \mathrm{cm})$ for polluting the test insulator. Now artificially polluted test insulator is mounted in the pollution chamber and is exposed to the steam for about 20 minutes with humidity of about 90 to $95 \%$.

Test Procedure: The test insulator is artificially polluted uniformly for a required ESDD and exposed to the steam for 20 minutes. Then a low voltage is applied and increased gradually until flashover occurs and experiment is repeated for 3 trials for the same ESDD. Now the experiment is repeated by applying the lowest flashover voltage among the three flashover voltages to the insulator for a time of 15 minutes. If the insulator flashes before said time then experiment is repeated by decreasing the voltage by $5 \%$ and is applied to the test insulator again for 15 minutes. If insulator does not flash then the voltage is increased by $2 \%$ and is applied for 15 minutes, this is repeated for 5 times for a given ESDD. Here the lowest flashover voltage in the entire sequence is treated as flashover voltage. The above discussed procedure is repeated for different ESDD for both test insulators. The flashover voltages for different ESDD obtained for both the insulators are plotted and is shown in the figure 2 .

Table 2 Dimensional details of insulators used in the experiments

\begin{tabular}{|c|c|c|c|c|}
\hline $\begin{array}{c}\text { Type of } \\
\text { Insulator }\end{array}$ & $\begin{array}{c}\text { Total } \\
\text { leakage } \\
\text { Distance } \\
(\text { L) } \text { cm }\end{array}$ & $\begin{array}{c}\text { Insulator } \\
\text { Diameter } \\
(\boldsymbol{D}) \text { cm }\end{array}$ & $\begin{array}{c}\text { Height } \\
(\text { H) } \text { in } \text { cm. }\end{array}$ & $\begin{array}{c}\text { Form Factor } \\
\text { (Calculated })\end{array}$ \\
\hline A & 30.5 & 25.5 & 13.5 & 0.77 \\
\hline B & 35.7 & 25.4 & 15.0 & 0.73 \\
\hline
\end{tabular}

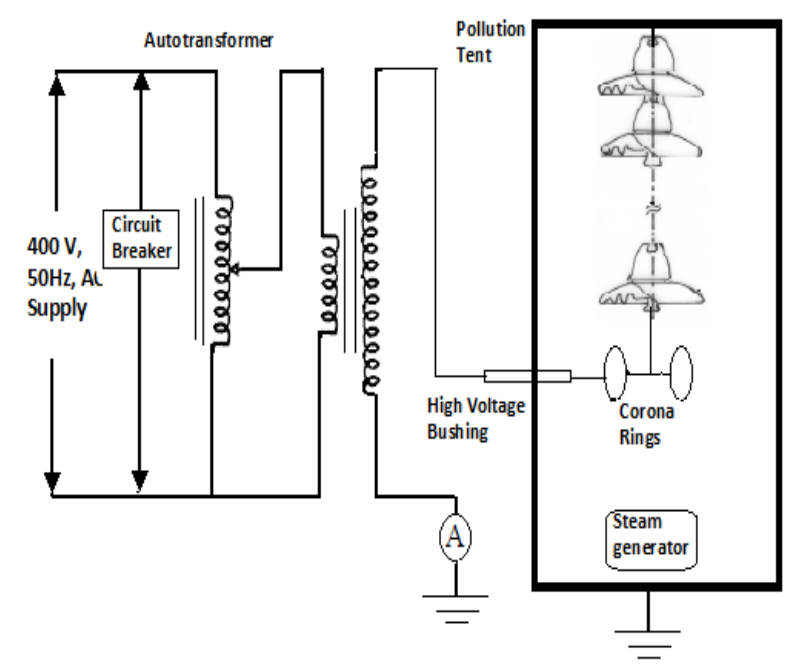

Fig. 1 Arrangement of the experimental set up

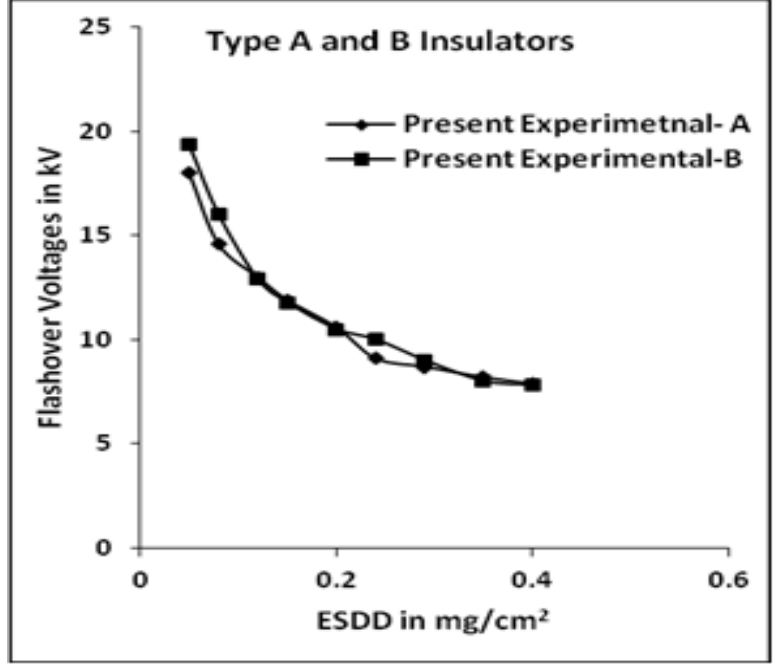

Fig. 2 Experimental Flashover voltages against ESDD for both Type A and Type B insulators

\section{DETERMINATION OF DIMENSIONAL CONSTANT ' $K$ '}

The dimensional constant $\mathrm{K}$ is determined using experimental data of flashover voltages using equation (14) for both type A and type B insulators. The Value of $\mathrm{K}$ is found to be in the range 0.55 to 0.57 and 0.54 to 0.55 for Type A and Type B insulators respectively. To represent the obtained range of $K$ value in terms of dimensions of insulator, a detailed study of dimensions of Insulators of Type A and B is done and as a result of the study it is found that the dimensional combination $\left(\frac{r}{L}\right)^{n}$ is very close to the range of values of K obtained experimentally. Therefore the dimensional constant is given by

$K=\left(\frac{r}{L}\right)^{n}$

Where ' $r$ ' is the radius of the insulator, ' $L$ ' is the total leakage distance and ' $n$ ' is the arc constant.

Now the equation (14) can be written as $V_{f o}$

$=\left(\frac{r}{L}\right)^{n} A^{\frac{1}{n+1}}\left(\frac{F F}{\left(86 * E S D D^{0.9}\right)\left(L-\left(L_{\text {arc }}\right)_{c}\right)}\right)^{\frac{n}{n+1}}\left(\left(L_{\text {arc }}\right)_{c}\right)$

The developed model (21) is to be verified for its correctness consequently, next section explains the results and discussions.

\section{RESULTS AND DISCUSSIONS}

To ensure the correctness of the model (21) proposed, flashover voltages for different ESDD are computed for the two insulators Type A and Type B whose dimensional details are given in Table II. The computed flashover voltages are compared with the present experimental flashover voltages obtained in the section IV for the same insulators and are shown in figure 3. 


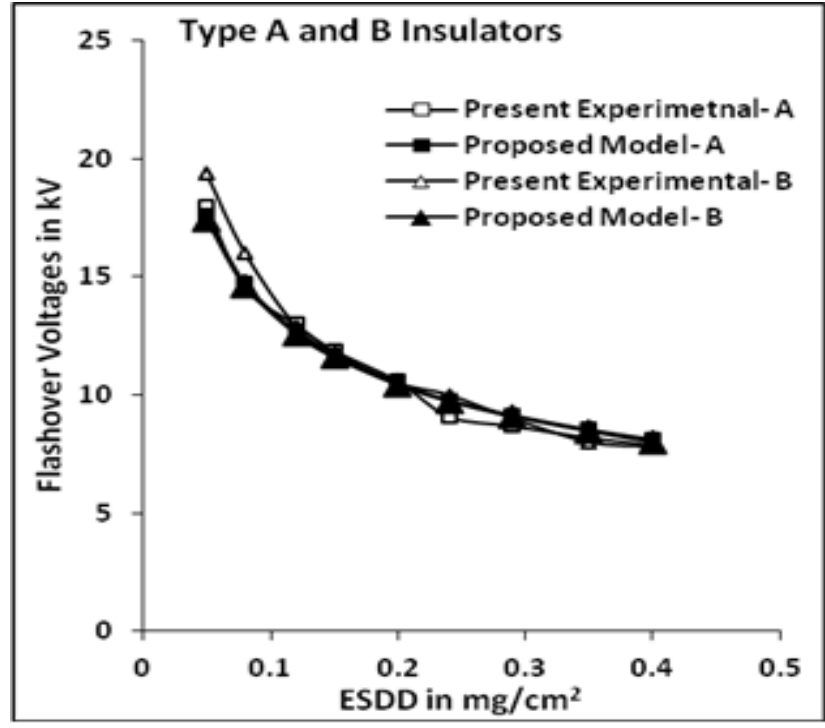

Fig. 3 Comparison of flashover voltages of present experimental and proposed model for Type A and B Insulator

From the figure 3 , it can be observed that between present experimental and proposed model results, there is a maximum of $4.7 \%$ deviation for Type $\mathrm{A}$ insulator and a maximum of $9.8 \%$ for Type $\mathrm{B}$ insulator. This shows that both model and experimental results are in good agreement for both Type A and Type B insulators.

\section{VALIDATION OF THE MODEL}

The proposed model is verified for its validity by comparing the model results with previous researchers experimental and model results $[14,15,37,38]$. The dimensional details of the insulators considered in the study are given Table 3 . The insulators are designated as Type A, B, C, D, E, F, G, H, I, J, K, L, M and N. The proposed model results are compared with experimental results of Insulators from Type A to F and also compared with analytical model results of Insulators from Type $\mathrm{G}$ to $\mathrm{N}$.

Table 3 Dimensional Details of Insulators considered in the study

\begin{tabular}{|c|c|c|c|c|c|}
\hline $\begin{array}{c}\text { Insulato } \\
\text { r Named } \\
\text { as }\end{array}$ & $\begin{array}{c}\text { Type of } \\
\text { Insulator } \\
\text { [Reff.] }\end{array}$ & $\begin{array}{c}\text { Heig } \\
\text { ht } \\
(H) c \\
m\end{array}$ & $\begin{array}{c}\text { Total } \\
\text { leakag } \\
e \\
\text { Distan } \\
\text { ce } \\
(L) \mathrm{cm}\end{array}$ & $\begin{array}{c}\text { Insulat } \\
\text { or } \\
\text { Diame } \\
\text { ter } \\
\text { (D) cm }\end{array}$ & $\begin{array}{c}\text { Form } \\
\text { factor } \\
\text { (Calculat } \\
\text { ed })\end{array}$ \\
\hline A & $\begin{array}{l}\text { Cap and } \\
\text { Pin1[14] }\end{array}$ & 30.5 & 25.5 & 13.5 & 0.77 \\
\hline B & $\begin{array}{l}\text { Cap and } \\
\text { Pin2[14] }\end{array}$ & 35.7 & 25.4 & 15.0 & 0.73 \\
\hline C & $\begin{array}{l}\text { Cap and } \\
\text { Pin3[14] }\end{array}$ & 30.7 & 25.4 & 11.5 & 0.82 \\
\hline D & $\begin{array}{c}\text { Fog Type1 } \\
{[15]}\end{array}$ & 14.6 & 43.1 & 25.4 & 0.916 \\
\hline E & $\begin{array}{c}\text { Cap } \\
\& \text { Pin4 } \\
{[15]}\end{array}$ & 14.6 & 30.5 & 25.4 & 0.696 \\
\hline
\end{tabular}

\begin{tabular}{|c|c|c|c|c|c|}
\hline $\mathrm{F}$ & $\begin{array}{c}\text { Cap \& } \\
\text { Pin5[38] }\end{array}$ & 14.6 & 27.9 & 25.4 & 0.684 \\
\hline G & $\begin{array}{c}\text { Cap \& } \\
\text { Pin6[37] }\end{array}$ & 15.9 & 33 & 26.8 & 0.79 \\
\hline $\mathrm{H}$ & $\begin{array}{c}\text { Fog Type } 2 \\
{[37]}\end{array}$ & 16.5 & 40 & 20 & 1.29 \\
\hline I & 7k3[37] & 18.5 & 30.4 & 28.8 & 0.68 \\
\hline $\mathrm{J}$ & $\begin{array}{c}\text { Bullers } \\
\text { [37] }\end{array}$ & 14 & 41.8 & 29 & 0.9 \\
\hline $\mathrm{K}$ & F7[37] & 14.6 & 31.1 & 25.5 & 0.7 \\
\hline $\mathrm{L}$ & $\begin{array}{c}\text { 80F140W[ } \\
37]\end{array}$ & 14 & 41.5 & 28 & 0.9 \\
\hline M & $\begin{array}{c}\text { U100L } \\
\text { [37] }\end{array}$ & 14.6 & 30 & 25.5 & 0.69 \\
\hline $\mathrm{N}$ & $\begin{array}{c}\text { U70BL } \\
{[37]}\end{array}$ & 14.6 & 25.5 & 28 & 0.68 \\
\hline
\end{tabular}

Figure 4 shows a comparison of flashover voltages Vs ESDD for Type A, B and C insulators between proposed model and experimental [14]. From the figure 3 it can be observed that present model predicts the flashover voltages with a deviation of less than $10 \%$ in comparison with experimentally [15] obtained flashover voltages for Type A, B and C insulators except for Type $\mathrm{B}$ insulator the prediction is having a maximum deviation of $21 \%$ at lower ESDD levels. Figure 5 shows a comparison of flashover voltages as a function of pollution severity in terms of ESDD $\left(\mathrm{mg} / \mathrm{cm}^{2}\right)$ between experimental $[15,38]$ and proposed model for Type D, $\mathrm{E}$ and $\mathrm{F}$ Insulators.

The comparison shows clearly that the deviation between experimental [15, 38] and proposed model results is within $10 \%$ for the above three insulators under varying pollution conditions.

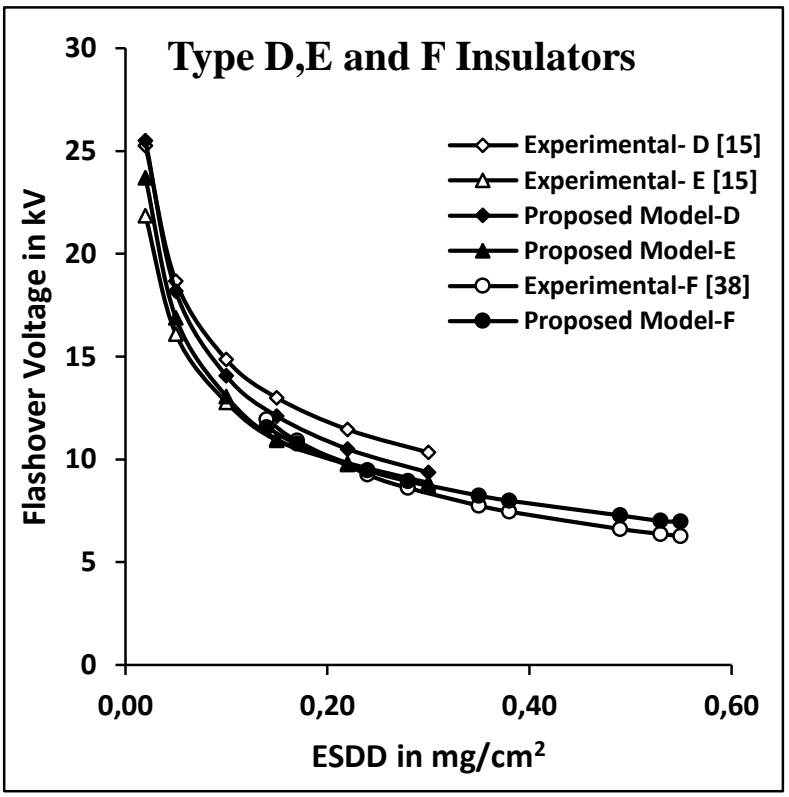

Fig. 5 Comparison of flashover voltages of experimental [15, 38 ] and proposed model for Type D to F Insulators 


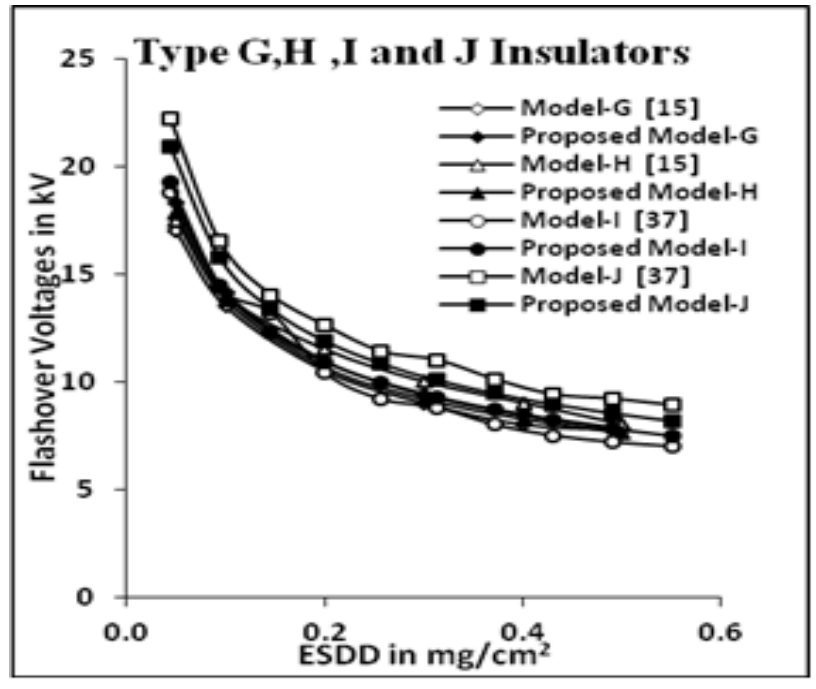

Fig. 6 Comparison of flashover voltages of model $[15,37]$ and proposed model for Type $\mathrm{G}$ to $\mathrm{J}$ Insulators

Figure 6 depicts the relation between flashover voltages and pollution condition represented as $\operatorname{ESDD}\left(\mathrm{mg} / \mathrm{cm}^{2}\right)$ between theoretical results of other researchers [15, 37] and proposed model results for the Insulators of Type G, H, I and $\mathrm{J}$ The relation exhibits a deviation of less than $10 \%$ between theoretical results of other researchers [15, 37] and present model. This comparison indicates that theoretical results of other researchers $[15,37]$ and present model are in good agreement with each other.

Figure 7 illustrates a comparison of flashover voltages Vs ESDD for Type K, L, M and N insulators between model [37] and present model results. From the characteristics it can be observed that a deviation of less than $10 \%$ is found between analytical results of other researchers [37] and present model results. Therefore proposed model results are very close to the model [37] results for the said Insulators.

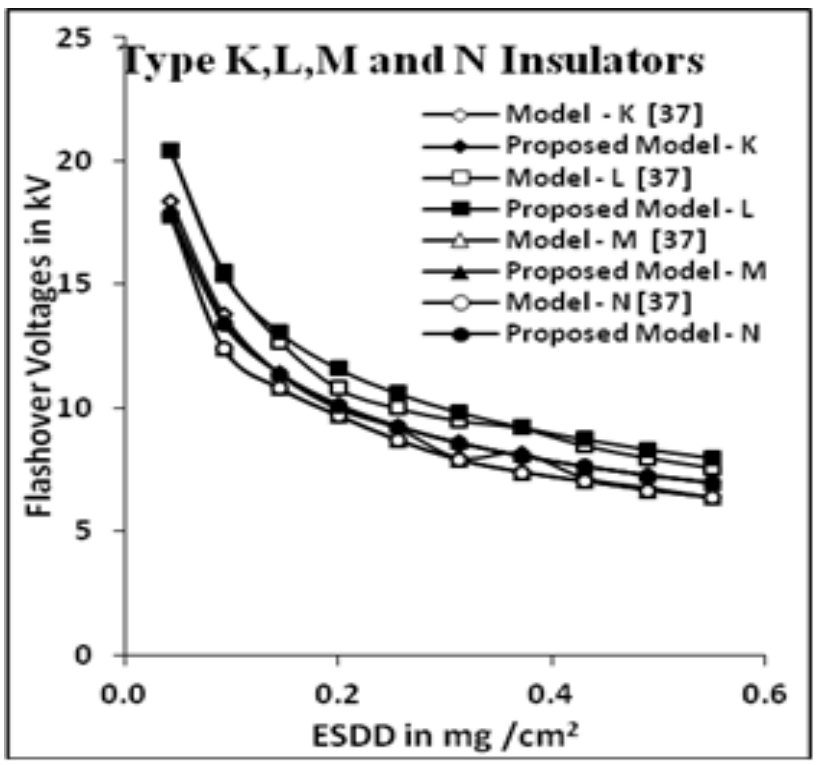

Fig. 7 Comparison of flashover voltages of Model [37] and proposed model for Type $\mathrm{K}$ to $\mathrm{N}$ Insulators

\section{CONCLUSIONS}

The present paper discusses the development of a mathematical model to predict the pollution flashover voltages of porcelain disc insulators. The model involves the main dimensions of the insulator, form factor, pollution level and Ayrton's arc constants. The developed model has been used to predict the flashover voltages of 14 different disc insulators and prediction shows, about $10 \%$ deviation in comparison with other researchers experimental and analytical model results. The proposed model would be very much useful in predicting the pollution flashover voltages of porcelain disc insulators for a given pollution severity. It also helps in the selection of insulators for different pollution conditions.

\section{ACKNOWLEDGEMENT}

The authors are grateful to Jain University, Principal, HOD and management of Acharya Institute of Technology and M S Ramaiah Institute of Technology, Bangalore for their constant support and encouragement in carrying out this research work.

\section{REFERENCES}

[1] MINNAARA, U.J. B. - GAUNTB, C.T. - NICOLLS, F.: "Characterisation of power system events on South African transmission power lines", Electric power systems research, Vol.82, Issue 1, pp.25-32, January

[2] SLAMA, EL-A. M. - BEROUAL, A. - HADI, H.: "Analytical Computation of Discharge Characteristic Constants and Critical Parameters of Flashover of Polluted Insulators", IEEE Trans. on Dielectrics and Electrical Insulation, Vol.17, No.2, pp 1764-1771, December 2010

[3] SIMA, W. - QING YANG - GAOQUAN,M. CHILONG JIANG - LIANG WU - HAO CHENG: "Experiments and Analysis of Sand Dust Flashover of the Flat Plate Model", IEEE Trans. on Dielectrics and Electrical Insulation, Vol.17, No.2, pp 572-581, April, 2010

[4] VOLAT, C. - FARZANEH, M. - MHAGUEN,N.: "Improved FEM Models of One- and Two-arcs to Predict AC Critical Flashover Voltage of Ice-covered Insulators", IEEE Trans. on Dielectrics and Electrical Insulation, Vol.18, No.2, pp 393-400, April, 2011

[5] JIAN LI - ZHICHENG GUAN - LIMING WANGHAILONG YANG: "An Experimental Study of AC Arc Propagation over a Contaminated Surface An Experimental Study of AC Arc Propagation over a Contaminated Surface", IEEE Trans. on Dielectrics and Electrical Insulation, Vol.17, No.4, pp 13601368, August, 2012

[6] SABRI, Y. - FARZANEH, M. - ZHANG, J.: "Application of Identification Methods for Predicting the Flashover Voltage of Contaminated Insulators Covered with Ice", IEEE Trans. on Dielectrics and Electrical Insulation, Vol. 17, No. 2, pp 451-457, April 2010 
[7] YAWEI LI - HAO, Y. -QIAOGEN, Z. - XIAOLEI, Y. - XINZHE YU: "Pollution Flashover Calculation Model Based on Characteristics of AC Partial Arc on Top and Bottom Wet-polluted Dielectric Surfaces", IEEE Trans. on Dielectrics and Electrical Insulation, Vol. 21, No. 4, pp 1735-1746, August 2014

[8] ZEGNINI, B. - BELKHEIRI, M. - MAHI, D.: "Modeling Flashover Voltage (FOV) of Polluted HV Insulators Using Artificial Neural Networks (ANNs)", International Conference on Electrical and Electronics Engineering, pp 336-340, 5th -8th November 2009

[9] GENCOGLU, M. TUNAY - MURAT UYAR: "Prediction of flashover voltage of insulators using least squares support vector machines", Expert Systems with Applications, 36, pp.10789-10798, February 2009

[10] ASIMAKOPOULOU, G. E. - KONTARGYRI, V. T. - ELIAS, CH. N. - ASIMAKOPOULOU, F. E. STATHOPULOS, I. A.: "A fuzzy logic optimization methodology for the estimation of the critical flashover voltage on insulators", Electric power systems research,81,pp- 580-588, October 201

[11] VOLAT, C. - FARZANEH, M. - MHAGUEN, N.: "Calculation of Critical Flashover Voltage of IceCovered Insulators Using the Finite Element Method", Annual Report Conference on Electrical Insulation and Dielectric Phenomena, pp 450-453, October 2009

[12] VOLAT, C. - FARZANEH, M. - MHAGUEN, N.: "Improved FEM Models of One- and Two-arcs to Predict AC Critical Flashover Voltage of Ice-covered Insulators",IEEE Trans. on Dielectrics and Electrical Insulation, Vol.18, No.2, pp 393-400, April, 2011

[13] MOULAL, B. - MEKHALDIL, A. - TEGUARL, M. - HADDAD, A.: "Characterization of Discharges on non-Uniformly Polluted Glass Surfaces Using a Wavelet Transform Approach", IEEE Transactions on Dielectrics and Electrical Insulation, Vol. 20, No. 4, pp. 1457-1466 August 2013

[14] PRADIPKUMAR, D. - KRISHNAN, V. NAGABHUSHANA, G. R.: "A New Mathematical Model for flashover voltages of polluted porcelain insulators", (Paper ID 7071), Paper A-6-4, Proc. Of 2010 International Conference on High Voltage Engineering and Applications (ICHVE 2010), New Orleans, USA, October 11th - 14th , 2010, pp. 493496.

[15] TOPALIS, F. V. -GONOS, I. F. - STATHOPULOS, I. A.: "Dielectric behaviour of polluted porcelain insulators", Proc. of IEE, Gener.Tranm.Distrib. Vol.148, No.4, pp. 269 - 274, July 2001

[16] LANGHAAR, H. L.: "Dimensional Analysis and Theory of Models", New York, Wiley, 1951

[17] IEC 507, “Artificial pollution tests on high voltage insulators to be used on AC systems", No.1, 1991

[18] RIZK, F. A. M.: "Mathematical models for pollution flashover", Electra, No.78, pp. 71-103, 1981
[19] PRADIPKUMAR DIXI: "Studies on Pollution Performance of Ceramic Insulators", A thesis submitted to Visvesvaraya Technological University, 2009

[20] OBENAUS, F.: "Fremdschichtüberschlag und riechweglänge", Deutsche Electrotechnik, Vol. 4, pp. 135-136, 1958

[21] ALSTON, L. L. - ZOLEDZIOWSKI, S.: " "Growth of Discharges on Polluted Insulation", Proc. IEE, Vol. 110, pp. 1260-1266, 1963

[22] CLAVERIE, P.: "Predetermination of the Behaviour of Polluted Insulators", IEEE Trans. Power App. Syst., Vol. 90, pp. 1902-1908, 1971

[23] JOLLY, D. C. - CHENG, T. C. - OTTEN: "Dynamic theory of discharge growth over contaminated insulator surfaces", Conf. paper No. C 74 068-3, IEEE PES winter meeting, New York, Jan 27 - Feb 1, 1974.

[24] RUMELI, A.: "Flashover along a water column" IEEE Trans. On Electrical Insulation, Vol.E1-11, Issue. 2, pp. 115-120, 1976

[25] RAHAL - HURAUX, C.: "Flashover mechanism of high voltage insulators", IEEE Trans. On power apparatus \& systems, Vol. PAS-98, Issue-6, pp. 22232231,1979

[26] EL-ARABATY - NOSSEIR, A. - EL-DEBEIKY, S. - NASSER, E. - EL-SHARKAWI, E. - EL-SARKY, A.: "Application of Infra-Red Thermography to the Study of Temperature Distribution on Energized Polluted Insulators", IEEE Transactions on Electrical Insulation, Volume:EI-14 ,Issue: 5,pp 278-280,1979

[27] VERMA, M. P.: "Mechanism of ac flashover on polluted insulators", Conf. paper, No.1.04, ISPPISD 1981, Feb 26-27, IIT, Madras, 1981.

[28] GUAN, Z. - ZHANG, R.: "Calculation of DC and AC flashover voltage of polluted insulators", IEEE Transactions on Electrical Insulation, Volume:25 , Issue:4 ,pp 723-729,1990

[29] SINGH, R. P. - SINHA, J. N.: "Simulation studies on Pollution Performance of Insulators", Journal of the IE (India), vol.75, pp. 26-34, May 1994

[30] GHOSH, P. J. - CHATTERJEE, N.: "Polluted insulators flashover for AC voltage", IEEE Trans. Dielectr. Electr. Insul. Vol. 2, pp. 128-136, 1995

[31] HUSSEIN HEMMATJOU: "Modeling of Ac Arc inside Wet Snow", A Thesis Submitted to the Université du Québec à Chicoutimi, 2006

[32] FARAG, A. S. - SHWEHDI, M. H. - CHENG, T. C.:, "Interfacial breakdown on contaminated electrolytic surfaces” ,Electrical Insulation conference,pp-789794, 1997

[33] FARZANEH, M. - LI, Y. - ZHANG, J. - FIKKE, S. M.: "Effect of low pressure on V-I characteristics of $\mathrm{AC}$ arc on ice surfaces", Annual report conference on Electrical Insulation and Dielectric Phenomena, Vol. 1,pp 250-254, 2000 
[34] HOLTZHAUSEN, J. P. - VOSLOO, W. L.: "The pollution flashover of ac energized post type insulators", IEEE Trans. Dielectrica and Electrical insulation, vol.8,Issue-2,pp-191-194,2001

[35] GONOS, I. F. - TOPALIS, F. V. STATHOPOULOS, I. A.: "Genetic algorithm approach to the modelling of polluted insulators",IEE proceedings Generation, Transmission and Distribution,vol.149, Issue-3,pp.373-376, 2002

[36] ZEGNINI, B. - MAHI, D. - MARTINEZ-VEGA, J.: "Modelling AC Arcs Developing along Electrolytic surfaces simulating practical polluted insulator using an original laboratory model", International Journal of Applied Engineering Research, vol.2, No.(1), 2007, pp.109 - 124 .

[37] GENCOGLU, M. T. -CEBECI, M.: “Computation of AC flashover voltage of polluted $\mathrm{HV}$ insulators using a dynamic arc model", European Transactions on Electrical Power Vol.19, Issue 5, pp. 689-701, July 2009.

[38] ZHICHENG, G. - RENYU, Z.: 'Calculation of DC and AC flashover voltage of polluted insulators', IEEE Trans. Electr. Insul. 1990, 25, (4), pp. 723-729
Received December 8, 2014, accepted March 30, 2015

\section{BIOGRAPHIES}

Chandrashekhar A Badachi was born in Jamkhandi, Bagalkot, Karnataka, India on $12^{\text {th }}$ November $1977 . \mathrm{He}$ received $\mathrm{BE}$ (Electrical) from Karnataka University, Dharwad in the year 2000 and M.Tech (VLSI design and Embedded system) from VTU, Belgaum, Karnataka in the year 2008. He is pursuing his doctoral degree in Outdoor Insulation. His research interests are High voltage, Outdoor Insulation, Electric field analysis and Reliability assessment.

Pradipkumar Dixit was born in Bijapur, Karnataka, India on $15^{\text {th }}$ August 1964. He received BE (Electrical) from Mysore University in the year 1989 and M.Tech (Power \& Energy Systems) from NITK, Surtkal in the year 1995. He obtained doctoral degree in the field of Outdoor Insulation from VTU, Belgaum in the year 2009. His research interests are High Voltage Engineering (Outdoor Insulation), Solid insulation, Electromagnetic Fields, Artificial Intelligence to Power Systems, Power Quality issues. 